\title{
Deep fat fried carrot powder incorporated wheat, rice and gram flour based snack food
}

Krishna Kumar Patel, S.A. Liaquati and Yashwant Kumar Patel

Received : 10.04.2018; Accepted : 13.04.2018

See end of the Paper for authors' affiliation

Correspondence to :

Krishna Kumar Patel Department of Post Harvest Engineering and Technology, Aligarh Muslim University, Aligarh (U.P.) India Email : k_krishna_374@ yahoo.co.in
- Abstract : Storage studies of snack foods, developed from the three combinations of cereals (rice and wheat) flour, legume (gram) flour and vegetable (carrot) powder, were conducted in this research. These snack foods were packed in high density polyethylene (HDPE) and aluminum foil (AF) pouches and kept at ambient temperature $\left(28 \pm 2^{\circ} \mathrm{C}\right)$ and relative humidity $(65 \pm 2 \% \mathrm{RH})$. The shelf life of samples was analyzed on the basis of bio-chemical properties; moisture content (MC), free fatty acids (FFA), peroxide value (PV) and thiobarbutyric acid (TBA) at every 15 days of intervals along with sensorial characteristics for 90 days. The moisture content, FFA, PV and TBA were found to be increased linearly in both pouches during the storage. All parameters, except FFA $\left(\mathrm{R}^{2}>0.62\right)$, were found to be correlated strongly $\left(\mathrm{R}^{2}>0.88\right)$ with storage periods. The sample packed in AF pouches had superior quality than the samples packed in HDPE pouches. However, no consistent pattern was observed for sensorial characteristics. All samples were found acceptable after 90 days of storage.

- Key words : Snacks, Carrot flour, FFA, PV, TBA, Storage

- How to cite this paper : Patel, Krishna Kumar, Liaquati, S.A. and Patel, Yashwant Kumar (2018). Deep fat fried carrot powder incorporated wheat, rice and gram flour based snack food. Internat. J. Agric. Engg., 11(Sp. Issue) : 1-10, DOI: 10.15740/HAS/IJAE/11.Sp. Issue/1-10. 